\title{
Trypanosoma cruzi: Serum levels of nitric oxide and expression of inducible nitric oxide synthase in myocardium and spleen of dogs in the acute stage of infection with metacyclic or blood trypomastigotes
}

\author{
Paula Melo de Abreu Vieira a , Amanda Fortes Francisco a , Sheler Martins de Souza a \\ Luiz Cosme Cotta Malaquias ${ }^{\mathrm{b}}$, Alexandre Barbosa Reis ${ }^{\mathrm{a}, \mathrm{d}}$, Rodolfo Cordeiro Giunchetti ${ }^{\mathrm{a}, \mathrm{c}}$, \\ Vanja Maria Veloso ${ }^{\mathrm{a}, \mathrm{d}}$, Marta de Lana ${ }^{\mathrm{a}, \mathrm{d}}$, Washington Luiz Tafuri ${ }^{\mathrm{a}}$, Cláudia Martins Carneiro ${ }^{\mathrm{a}, \mathrm{d}, *}$

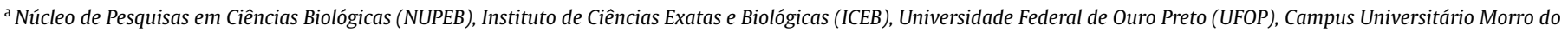 \\ Cruzeiro, 35 400-000 Ouro Preto, MG, Brazil \\ ${ }^{\mathrm{b}}$ Núcleo de Pesquisa em Imunologia, Bloco F13, Campus Antônio Rodrigues Coelho, 35020-220, Universidade Vale do Rio Doce (UNIVALE), Governador Valadares, MG, Brazil \\ ${ }^{\mathrm{c}}$ Departamento de Ciências Biológicas, ICEB, UFOP, Campus Universitário Morro do Cruzeiro, 35 400-000 Ouro Preto, MG, Brazil \\ d Departamento de Análises Clínicas, Escola de Farmácia, UFOP, 35 400-000 Ouro Preto, MG, Brazil
}

\section{A R T I C L E I N F O}

\section{Article history:}

Received 14 April 2008

Received in revised form 25 September 2008

Accepted 30 September 2008

Available online 18 October 2008

\section{Keywords:}

Chagas disease

Trypanosoma cruzi

Blood trypomastigotes (BT)

Metacyclic trypomastigotes (MT)

Nitric oxide (NO)

Inducible nitric oxide synthase (iNOS)

\begin{abstract}
A B S T R A C T
The participation of nitric oxide (NO) in the control of blood parasitemia and parasitism during the acute phase of infection in dogs inoculated with blood trypomastigotes (BT) or metacyclic trypomastigotes (MT group) of Berenice-78 Trypanosoma cruzi strain has been evaluated. Animals of the MT group $(n=4)$ presented increased levels of serum NO throughout the infection when compared with the BT $(n=4)$ or control $(n=4)$ groups, and a delay in parasitemia peak compared with the BT group. In spleen fragments, tissue parasitism was not observed but the MT group presented larger areas associated with inducible NO synthase (iNOS) in relation to BT and control groups. Heart fragments of MT-infected animals exhibited comparatively low tissue parasitism and high iNOS expression, while animals of the BT group presented high inflammatory infiltrate, high tissue parasitism and low iNOS expression. These results indicate that the source of inoculum can interfere with the development of the acute phase of Chagas disease, and may also trigger a distinct parasite-host interaction during this phase.
\end{abstract}

(c) 2008 Elsevier Inc. All rights reserved.

\section{Introduction}

Trypanosoma cruzi, the causative agent of Chagas disease, is characterised by a complex biological cycle involving an invertebrate vector and mammalian hosts. The protozoan exists in at least three morphologically distinct stages. Epimastigotes proliferate in the invertebrate host and are released as metacyclic trypomastigotes (MT) in the faeces. In the vertebrate host, amastigotes and blood trypomastigotes (BT) are the intracellular developmental and infective forms, respectively (Andrade and Andrews, 2005).

Transmission mechanisms include vectorial, transfusional and oral infection, congenital processes and laboratory accidents (Prata, 2001). Vectorial infection is the main and most frequent form of transmission and occurs when mucous membranes or abraded skin are exposed to MT-infected faeces of triatomine insects. In

"Corresponding author. Address: Núcleo de Pesquisas em Ciências Biológicas (NUPEB), Instituto de Ciências Exatas e Biológicas (ICEB), Universidade Federal de Ouro Preto (UFOP), Campus Universitário Morro do Cruzeiro, 35 400-000 Ouro Preto, MG, Brazil. Fax: +55 313559 1680, +55 3135591694 .

E-mail addresses: carneiro@ef.ufop.br, carneirocm@gmail.com (C.M. Carneiro). the domestic cycle of Chagas disease, Triatoma infestans and Rhodnius prolixus are the principal invertebrate vectors (Kollien and Schaub, 2000). Although the vertebrate host can develop a cellular and humoral immune response to the parasite, chronic infection is maintained by a reduced number of circulating BT forms. The presence of BT forms in the blood thus generates a further public health problem, and transmission of the parasite via blood transfusion has become the second most frequent route of infection (Coura et al., 2007). Transmission of $T$. cruzi resulting from congenital processes, oral infection or laboratory accidents may be mediated by either MT or BT forms (Sandler et al., 2003).

During the acute phase of infection, the destruction of trypomastigotes is dependent on the production of nitric oxide (NO), a process that is catalysed by inducible NO synthase (iNOS) (Vespa et al., 1994; Aliberti et al., 1996; Holscher et al., 1998). Studies have shown that glycosyl phosphatidylinositol-anchored mucin-like glycoproteins purified from BT forms (tGPI mucins) are potent elicitors of proinflammatory responses (i.e. cytokine and NO production) by IFN- $\gamma$ primed murine macrophages. In contrast, the corresponding glycoproteins derived from MT forms (mGPI mucins) are reported 
to be at least 100-1000-fold less active than tGPI mucins in the induction of NO by murine macrophages (Camargo et al., 1997a,b; Almeida et al., 2000). Recent studies from our group have revealed that BT and MT infections are associated with distinct parasitological and serological features, together with intrinsic and inoculum source-specific changes in circulating leukocytes (Carneiro et al., 2007).

The canine model is currently considered to provide an appropriate experimental system with which to investigate various aspects of Chagas disease, since Canis familiaris displays high susceptibility to infection and shows considerable similarities in the manifestation of the acute and chronic phases that are representative of the human disease. Moreover, it is possible to reproduce in this model the symptomatic acute phase and the chronic phase in both the undetermined and heart forms of the disease (Lana et al., 1988, 1992; Bahia et al., 2002). Using such a model system, we have recently demonstrated that MT forms of the Be-78 strain of T. cruzi (a strain isolated in 1978 from Berenice patient, in whom Chagas disease was first described) are more virulent than the BT forms (Bahia et al., 2002).

On the basis of the above, the canine model has been employed to investigate aspects of the participation of NO during the acute phase of experimental infection by MT forms, simulating vectorial transmission, and by BT forms, simulating transfusion transmission (or, indeed, any transmission mechanism involving BT forms) of Berenice-78 (Be-78) T. cruzi strain. The objective of the study was to obtain a better understanding of the mechanisms related to the pathogenesis of Chagas disease in the canine model.

\section{Materials and methods}

Details of the project were submitted to and approved by the Ethical Committee on Animal Research of the Universidade Federal de Ouro Preto. All procedures were carried out in compliance with current Brazilian regulations relating to Experimental Biology and Medicine as described in the guidelines issued by the Colégio Brasileiro de Experimentação Animal (COBEA, 2006). Study animals were maintained in the central animal facility at the Universidade Federal de Ouro Preto (UFOP), Minas Gerais, Brazil.

\subsection{Parasites, animals and experimental infection}

Two groups of four dogs were inoculated intraperitoneally with either MT or BT forms of strain Be-78 T. cruzi (2000 forms per kg body weight), obtained from nymphs of Triatoma infestans and Swiss mice, respectively. Four dogs were maintained uninfected as the control group.

\subsection{Parasitological parameters}

From days $1-35$, samples $(5 \mu \mathrm{L})$ of blood were collected daily from infected dogs by vein-puncture of ear veins. The numbers of parasites in the blood samples were determined under the optical microscope according to the method of Brener (1962), and parasitemia curves were plotted using the daily mean numbers of parasites per group of four animals.

\subsection{Serum levels of $N O$}

Peripheral blood ( $5 \mathrm{~mL}$ ) was collected from the brachial cephalic veins of experimental animals prior to inoculation and weekly thereafter (on days 7, 14, 21, 28 and 35), and serum was separated and stored frozen $\left(-70^{\circ} \mathrm{C}\right)$ until required for analysis. Levels of endogenously synthesised NO in the serum were assessed by reducing nitrate to nitrite with nitrate reductase $(1 \mathrm{U} / \mathrm{mL})$ followed by the Griess reaction (Green et al., 1982). Nitrite concentrations were determined by extrapolation from standard curves obtained using various concentrations of sodium nitrite, and the results were expressed in $\mu \mathrm{M}$.

\subsection{Histopathological examinations and immunohistochemical analyses}

Experimental animals were submitted to necropsy during the acute phase of infection, and fragments of the heart and spleen were resectioned, fixed in $10 \%$ buffered formalin $(\mathrm{pH} 7.2)$ and embedded in paraffin. Sections ( $5 \mu \mathrm{m}$ thick) were mounted on poly-L-lysine-coated glass slides and were either stained with Haematoxylin-Eosin (HE) for standard histological procedures, or submitted to immunohistochemical analysis.

\subsubsection{Expression of $i N O S$}

Endogenous peroxide was blocked by incubating embedded tissue sections with $3 \%$ hydrogen peroxide $\left(\mathrm{H}_{2} \mathrm{O}_{2}\right)$ in methanol. Sections were then heated in a microwave oven $(700 \mathrm{~W})$ and cooled to room temperature. After this, the sections were further blocked with normal horse serum (Vector Laboratories Burlingame, CA, USA), and then incubated overnight at $4{ }^{\circ} \mathrm{C}$ with the primary antibody against iNOS diluted 1:200 (Cat. No. sc-651; Santa Cruz Biotechnology Inc., Santa Cruz, CA, USA). The sections were incubated with the secondary antibody conjugated with biotin (Elite ABC Kit, Vector Laboratories), and then incubated with streptavidin-peroxidase complex. The reaction products of peroxidase were visualised by incubation with $3.3^{\prime}$-diaminobenzidine (DAB). Finally the sections were lightly counterstained with Harris's haematoxylin solution. Negative control slides were prepared in the same conditions but in the absence of the primary antibody.

\subsubsection{Determination of tissue parasitism}

Embedded tissue sections were incubated overnight at $4{ }^{\circ} \mathrm{C}$ with polyclonal anti-T. cruzi serum (obtained from a rabbit that had been immunised with T. cruzi Y strain) diluted 1:1000. Subsequently, sections were incubated with secondary antibody antirabbit IgG and peroxidase-anti-peroxidase complex, and the label was detected by incubation with DAB. Sections obtained from murine acute myocarditis, that were rich in amastigote nests, were used as positive controls. Finally the sections were stained for nuclei with diluted Harris's haematoxylin solution. Negative control slides were prepared in which the primary antiserum was substituted by PBS.

\subsection{Morphometric studies}

Morphometric studies of iNOS expression, inflammation and tissue parasitism were performed by analysing images of 20 randomly-selected fields (total area $1.5 \times 10^{6} \mu \mathrm{m}^{2}$ ) of tissue fragment sections on a single slide per animal. Inflammatory infiltration in the heart was quantified by counting the cell nuclei present in sections of heart fragments, while iNOS and T. cruzi immunoreactive areas were measured in sections of heart and spleen fragments. All analyses were performed using a 40X objective, and images were analysed with the aid of Leica QWin software (Leica Microsystems, Wetzlar, Germany).

\subsection{Statistical analyses}

Since the area beneath the parasitemia curve was non-parametric in character, comparative analyses between groups were performed using the Kolmogorov-Smirnov test (Conover, 1980). Serum levels of NO, iNOS expression and inflammatory infiltration were analysed amongst the different groups using one-way 
analysis of variance (ANOVA) and Tukey post-tests. Student's $t$-test was employed to determine the significance of differences in tissue parasitism. In all cases, differences were considered statistically significant when $P$ values were $<0.05$.

\section{Results}

\subsection{Production of NO and levels of parasitemia}

The dynamics of the levels of NO in serum collected from groups of experimental animals within the period commencing immediately before inoculation and for the following 35 days are presented in Fig. 1. Animals of the MT group showed significantly higher levels of NO when compared with those of the BT and control groups at days 14 and 28 after infection. In the MT group, enhanced production of NO began at day 7 but diminished after day 28 , while in the BT and control groups the levels of NO were similar throughout the 35 days. No significant differences in serum NO levels were observed in the longitudinal analyses. Although no significant differences were observed between groups MT and BT with respect to the areas under the parasitemia curves (Fig. 1), the early production of NO in MT-infected animals may be related to the later peak of parasitemia observed in this group.

\subsection{Heart inflammatory infiltration}

The results of the morphometric analysis of inflammatory infiltration in the heart are presented in Fig. 2A. Statistically significant increases were observed in the numbers of cell nuclei present in the heart fragments of MT- and BT-infected animals in comparison with those of the control group. Moreover, the numbers

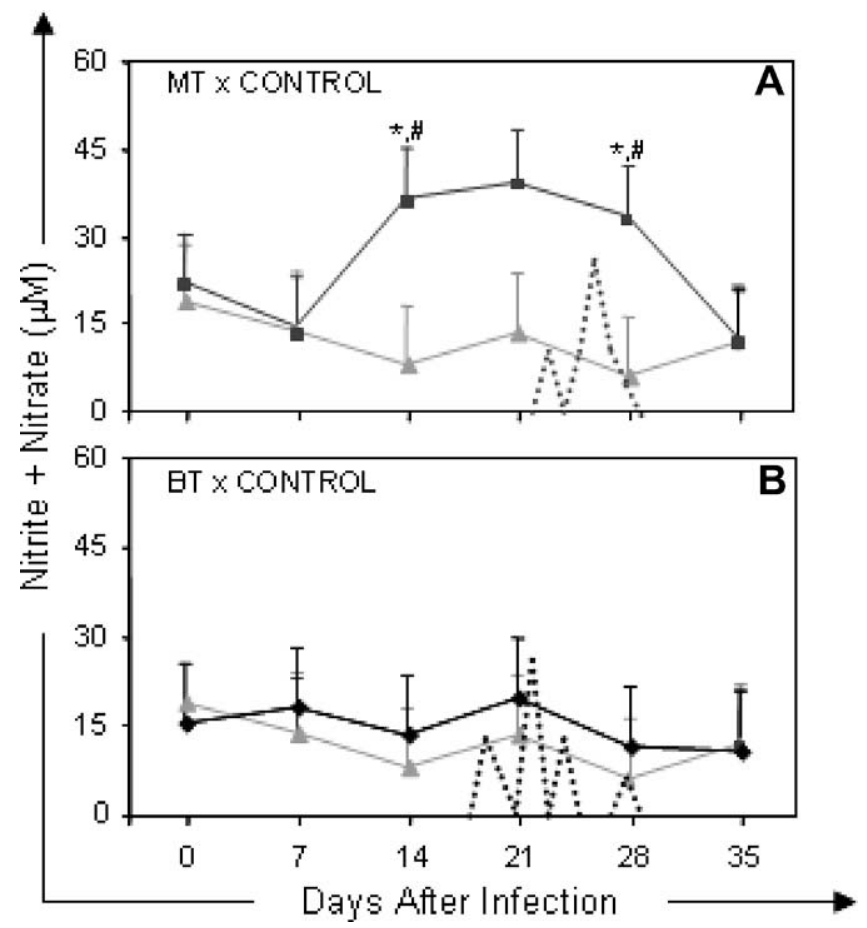

Fig. 1. Dynamics of the levels of nitric oxide (nitrite + nitrate) in canine serum versus parasitemia during acute infection with (A) metacyclic (_- _ ) and (B) blood trypomastigotes $(-)$ of Berenice-78 Trypanosoma cruzi strain in comparison with control dogs $(--)$. In A and B, the dotted lines represent the curves of parasitemia. The data shown are expressed as means $\pm \operatorname{SD}(n=4)$. Values in the MT group that are significantly different $(p<0.05)$ from those in the control group are marked with the $*$ symbol. Values in the MT group that are significantly different $(p<0.05)$ from those in the BT group are marked with the \# symbol. of inflammatory cells were greater in animals of the BT group compared with the MT group $(P<0.05)$. In infected animals, the inflammatory infiltrate comprised predominantly mononuclear cells (Fig. 3B and C), the majority of which exhibited the morphology of lymphocytes. However, animals of the MT group exhibited focal inflammatory infiltrates while in those of the BT group the inflammation was diffuse.

\subsection{Parasitological parameters}

The results of the quantitative evaluation of tissue parasitism in heart fragments derived from MT- and BT-infected animals are shown in Fig. 2B. Tissue parasitism was observed to be discreet in all infected animals, and morphometric analysis of different areas of heart tissue revealed no significant differences in parasitism between the two groups (Fig. 2B and insert Fig. 3B and C). No parasitism in spleen tissue was observed in animals of either group.

\section{4. iNOS expression in heart and spleen}

Immunohistochemical staining for iNOS was carried out after necropsy during the acute phase of infection. Results of the quantification of areas of sections of heart and spleen exhibiting iNOS immunoreactivity are shown, respectively, in Fig. 2C and D, while the histopathological aspects are displayed in Fig. 3. Heart fragments from animals of the MT group presented significantly larger iNOS positive areas compared with the control group. With respect to the BT group, however, the iNOS positive areas were not statistically different in size compared with either the MT or the control groups. In comparison with control animals, significant staining was detected in the arteries and arterioles in the heart fragments of infected animals (inserts to Fig. 3D-F). Moreover, a blush of iNOS immunoreactivity throughout the myocardium was observed in all infected animals, and was most intense in animals of the MT group (Fig. 3D-F).

With respect to spleen fragments, the pattern of iNOS expression was very similar to that established for levels of serum NO, i.e. MT-infected animals presented a significantly larger area of iNOS immunoreactivity compared with both the BT and the control groups (Fig. 2D). The white pulp was the region in which has focused most of the marked area for iNOS in the three experimental groups. However, the animals of MT group had a strong mark just below the capsule that was not observed in the other groups. Only in the BT group we observed a marked area for iNOS in the follicles.

\section{Discussion}

The aim of the present study was to evaluate serum NO levels, blood parasitemia, expression of iNOS and tissue parasitism in spleen and heart of dogs infected with MT or BT forms of Be-78 T. cruzi strain. Previous results from our laboratories have indicated that infection, via the intraperitoneal route, with MT forms of the Be-78 strain leads to a higher parasitemia peak compared with animals infected with BT forms (Bahia et al., 2002). This apparently controversial data may represent an age related phenomenon considering that the dogs included in the previous investigation were much younger (average age 60 days) than those presently evaluated (average age 120 days). Major changes in the immunological status of young puppies, involving maturation of the immune response, could be the putative key element contributing to the control of parasitemia levels in older animals.

The two infective forms of the parasite are known to exhibit distinct characteristics that induce different immune responses in vitro and in vivo (Brener and Gazzinelli, 1997; Carneiro et al., 2007). Infection mediated by metacyclic forms in vitro can, in part, mimic 
A
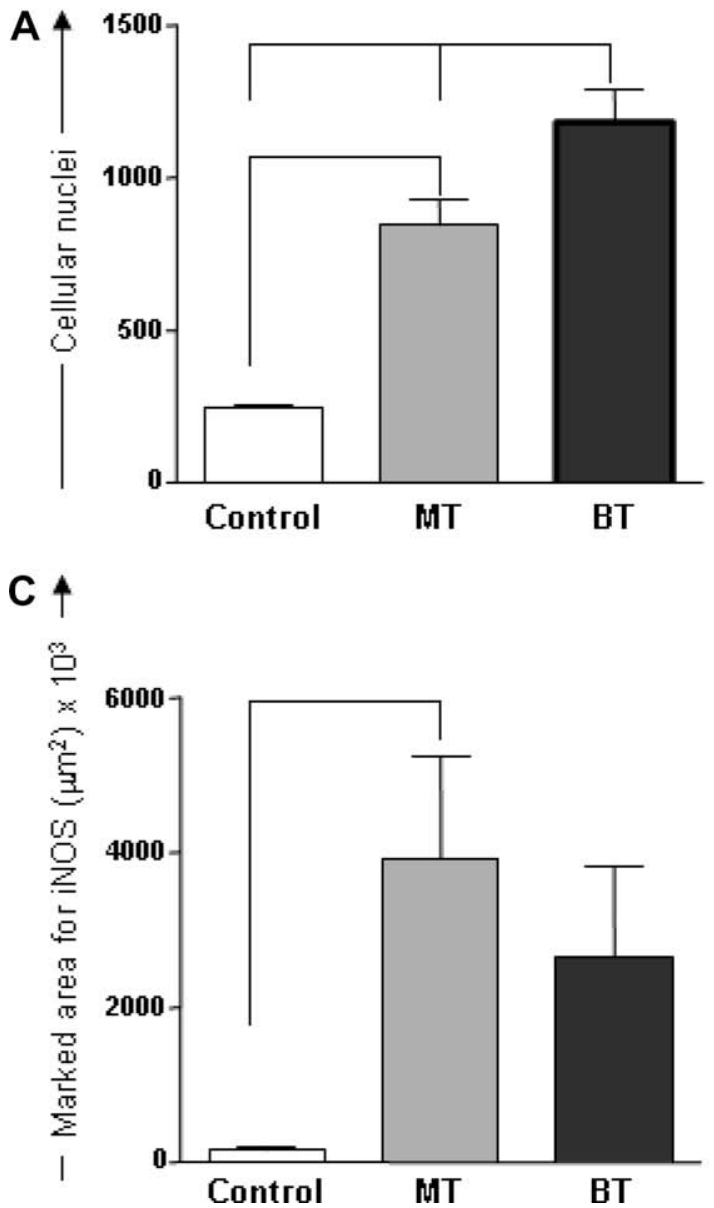

B

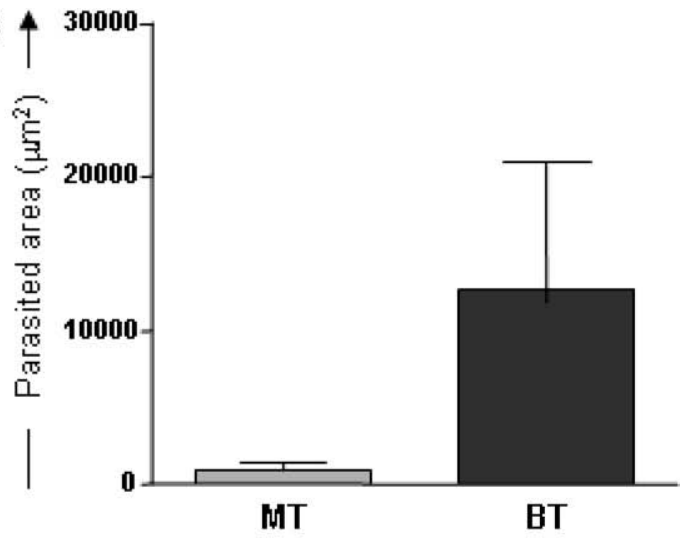

D

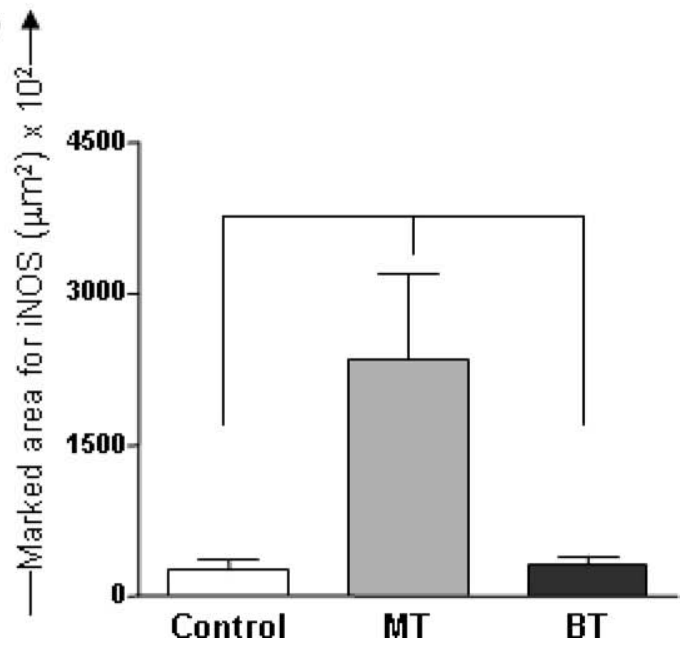

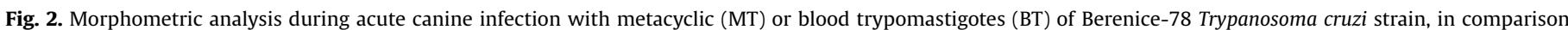

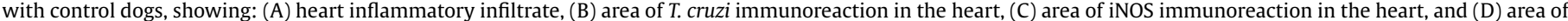

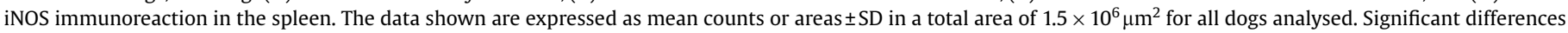
$(p<0.05)$ between groups are indicated by connecting lines.

that caused by vectors in vivo. On the other hand, in vitro infection with blood forms imitates blood transmission or even laboratory accidents. It is worth mentioning that the majority of experimental infections are conducted using blood trypomastigotes because these forms are easier to obtain and maintain in the laboratory.

The results obtained in the present study showed that dogs infected with MT forms of the parasite exhibited elevated expression of iNOS and higher serum levels of NO in comparison with BT-infected animals $(p<0.05)$.

Although iNOS is not considered essential for the control of T. cruzi infection (Cummings and Tarleton, 2004), the elimination of BT forms in the acute phase is dependent on a number of factors (Pascutti et al., 2003; Cardillo et al., 2007), one of which is the production of NO catalysed by iNOS (Vespa et al., 1994; Petray et al., 1995; Aliberti et al., 1996; Holscher et al., 1998). Thus macrophages infected with $T$. cruzi produce IL-12, a powerful cytokine that induces INF- $\gamma$ synthesis by NK cells. INF- $\gamma$ plays an important role in the activation of macrophages that produce high levels of NO and effectively control parasite replication (Cardillo et al., 1996; Sardinha et al., 2006).

The increases in serum levels of NO observed in the MT group could be related to the high expression of iNOS detected in different tissues (i.e. heart and spleen) that have direct contact with blood. In this manner, such compartments could contribute to the systemic increase in NO in the MT group. On the other hand, the differences in profile of serum NO observed between the MT and $\mathrm{BT}$ groups could arise from the parasite-host interaction initially established by the two infective forms, since towards the end of the acute phase the differential effect had disappeared.

It was demonstrated that, in a murine model, tGPI-mucins of BT forms are potent elicitors of the immune system and produce large amounts of NO (Camargo et al., 1997a,b). The disparity between these two sets of findings could be due to the experimental model used (i.e. dogs versus mice) or to the type of experiment (i.e. in vitro versus in vivo) carried out. Additionally, the earlier work focused on a single component of the parasite form whereas in the present investigation all components were involved.

Parasite clearance in peripheral blood was observed simultaneously in MT- and BT-infected animals on day 28 following inoculation, and would account for the observed similarities between the MT and BT infection profiles. This suggests, therefore, that the major inoculum-dependent immunological events take place early in the infection process. This was demonstrated in this study, because from the 28th day after infection, the serum levels of NO in animals of the MT group showed a decline, and at day 35 were similar to those of the BT and control groups. These findings are consistent with those reported by other author (Saeftel et al., 2001), who demonstrated that in the murine model NO was important for the control of infection in the first 3 weeks following infection, but declined in level thereafter.

Considering previous results of Carneiro et al. (2007) concerning the phenotyping of peripheral blood, a positive correlation between serum levels of $\mathrm{NO}$ and the frequency of $\mathrm{CD}^{+} \mathrm{T}$ lymphocytes and subpopulation $\mathrm{CD} 4^{+}$was observed only in animals of 

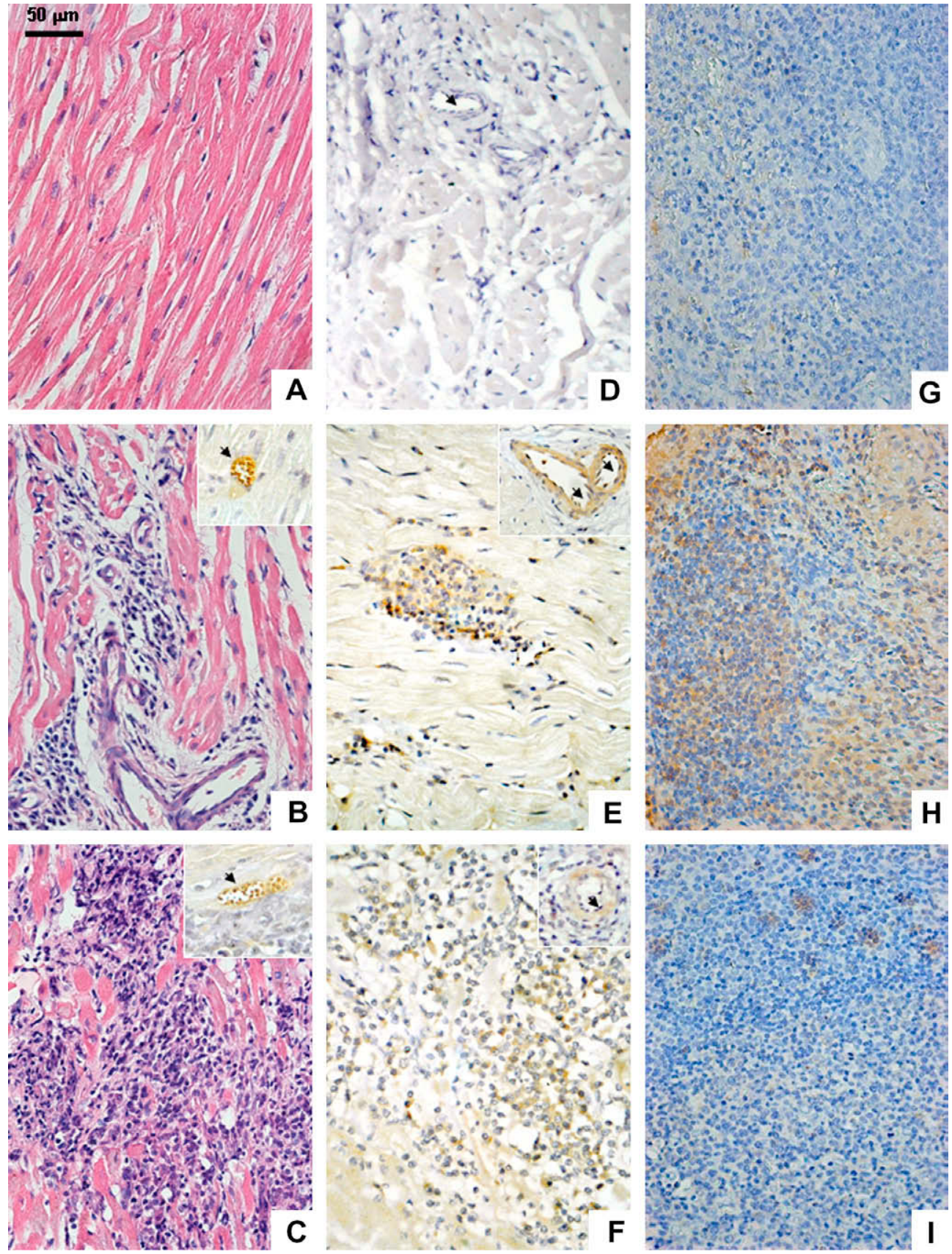

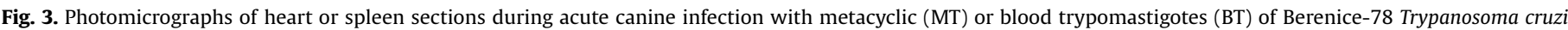

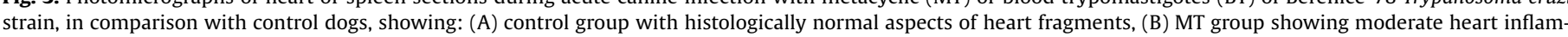

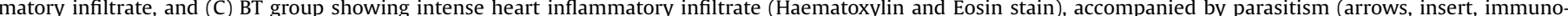

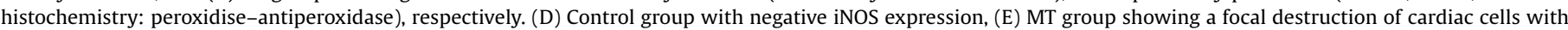

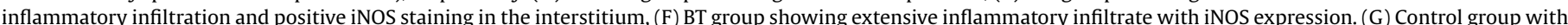

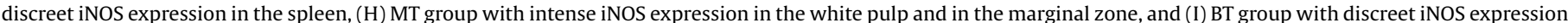
in the white pulp (iNOS-immunohistochemistry: streptavidin-biotinperoxidase). Bars $=50 \mu \mathrm{m}$.

the MT group (data not shown). This suggests that these cell types could be participating directly or indirectly in the production of $\mathrm{NO}$ in this group. $\mathrm{CD}^{+} \mathrm{T}$ cells could generate NO directly through the action of iNOS, as has been observed by Taylor-Robinson et al. (1994). Conversely, CD4 ${ }^{+}$T lymphocytes may produce INF- $\gamma$, which in turn activates macrophages to produce NO by the action of iNOS (Russo et al., 1988; Araujo, 1989; Rottenberg et al., 1993, 1995).

Additionally, Carneiro et al. (2007) observed that, in the experimental dogs employed in the present study, there was a significant decrease of $\mathrm{CD} 4^{+}$cells in the peripheral blood of MT-infected animals on day 28 in comparison with those of the BT group. Such a finding may indicate a greater migration of $\mathrm{CD} 4^{+}$cells to the sites of inflammation in the MT group, and this could be responsible for the increased production of NO in the tissues of MT-infected animals. Numerous attempts have been made by our research group to characterise the T cells $\left(\mathrm{CD}^{+}\right.$and $\left.\mathrm{CD}^{+}\right)$in heart and spleen samples, both frozen and embedded in paraffin, but currently without success.

Park et al. (2000) detected the presence of iNOS mRNA in cells from normal human heart, implying that heart muscles express iNOS constitutively under baseline conditions. This possibility would explain the expression of iNOS in different areas 
of the heart of control animals as observed in the present work. Immunohistochemical studies by Chandrasekar et al. (1998) revealed high expression of iNOS in the arteries and arterioles of rats commencing $36 \mathrm{~h}$ after infection but reducing by the 15 th day. In contrast, iNOS expression was intense in cardiomyocytes on the 15 th day after infection. The same pattern was observed in the present study, with strong expression in the arteries and especially in cardiomyocytes.

Animals of the BT group showed greater inflammatory process compared with the control and MT groups, but the areas associated with iNOS were, in general, smaller. This fact could be related to the presence of anti-inflammatory cytokines such as IL-10 and TGF- $\beta$ (Oswald et al., 1992; Sher et al., 1992), which can disable the macrophages and thus prevent expression of iNOS.

No parasitism was detected in spleen tissue fragments derived from any of the experimental dogs, a finding that could be explained by the myotropism observed in Be-78 $\mathrm{T}$. cruzi strain.

Since BT and amastigotes, but not MT and epimastigotes, are able to promote the synthesis of cytokines in macrophages and to activate different compartments of the immune system (Camargo et al., 1997a; Dos Reis et al., 2002), we hypothesized that, initially, MT may infect host cells in a silent manner. However, apparently, inoculation of animals with MT forms induces an effective initial response that limits parasitemia and subsequent tissue parasitism, resulting in a lower inflammatory response and only minor tissue damage. In contrast, infection with BT forms appears not to induce an early immune response that is sufficiently elaborate to achieve the rapid control of the infection, and this permits the development of intensive histological changes, especially in the heart. Will be performed by our group, in vitro studies to understand how the different infective forms change the pattern of expression of cytokines in cardiomyocytes and macrophages, trying to understand how the interaction between infective forms-host cells produces different immunological answers.

The results presented herein reinforce those obtained by Carneiro et al. (2007), who found that the source of inoculum could interfere with the development of the acute phase of Chagas disease in respect of parasitology, serology and phenotype of the peripheral blood cells. It is possible that the intrinsic pattern of parasite-host cell interactions triggered during the acute phase by different inoculum sources may influence various immunological aspects of Chagas disease.

Our findings emphasise the importance of taking into account the inoculum source of $T$. cruzi when attempting to transfer information from experimental models to human infection, since different inoculum sources may trigger distinct parasite-host interactions during the acute phase that may influence relevant biological aspects of chronic Chagas disease.

\section{Acknowledgments}

The authors wish to express their appreciation of the hard work carried out by the kennel staff of the Federal University of Ouro Preto, and for their special dedication during the execution of this project. The authors are also grateful to Rede Mineira de Bioterismo, Fundação de Amparo à Pesquisa do Estado de Minas Gerais and Conselho Nacional de Desenvolvimento Científico e Tecnológico (CNPq), Brazil.

\section{References}

Aliberti, J.C., Cardoso, M.A.G., Martins, G.A., Gazzinelli, R.T., Vieira, L.Q., Silva, J.S., 1996. IL-12 mediates resistance to Trypanosoma cruzi infection in mice and is produced by normal murine macrophage in response to live trypomastigote. Infection and Immunity 64, 1961-1967.

Almeida, I.C., Camargo, M.M., Procopio, D.O., Silva, L.S., Mehlert, A., Travassos, L.R., Gazzinelli, R.T., Ferguson, M.A.J., 2000. Highly purified glycosylphosphatidylinositols from Trypanosoma cruzi are potent proinflammatory agents. EMBO Journal 19, 1476-1485.
Andrade, L.O., Andrews, N.W., 2005. The Trypanosoma cruzi-host cell interplay: location, invasion, retention. Nature Reviews: Microbiology 3, 819-823.

Araujo, F.G., 1989. Development of resistance to Trypanosoma cruzi in mice depends on a viable population of L3T4+ (CD4+) T lymphocytes. Infection and Immunity 57, 2246-2248.

Bahia, M.T., Tafuri, W.L., Caliari, M.V., Veloso, V.M., Carneiro, C.M., George, L.L.M.C., Lana, M., 2002. Comparison of Trypanosoma cruzi infection in dogs inoculated with blood or metacyclic trypomastigotes of Berenice-62 and Berenice-78 strains via intraperitoneal and conjunctival routes. Revista da Sociedade de Medicina Tropical 35, 339-345.

Brener, Z., 1962. Therapeutic activity and criterion of cure in mice experimentally infected with Trypanosoma cruzi. Revista do Instituto de Medicina Tropical de São Paulo 4, 389-396.

Brener, Z., Gazzinelli, R.T., 1997. Immunological control of Trypanosoma cruzi infection and pathogenesis of Chagas' disease. International Archives of Allergy and Immunology 114, 103-110.

Camargo, M.M., Almeida, I.C., Pereira, M.E., Fergunson, M.A., Travassos, L.R., Gazzinelli, R.T., 1997a. Glycosylphosphatidylinisitol anchored mucin-like glycoproteins isolated from Trypanosoma cruzi trypomastigotes initiate the synthesis of proinflammatory cytokines by macrophages. Journal of Immunology 158 , 5890-5901.

Camargo, M.M., Andrade, A.C., Almeida, I.C., Travassos, L.R., Gazzinelli, R.T., 1997b. Glycoconjugates isolated from Trypanosoma cruzi but not from Leishmania species membranes trigger nitric oxide synthesis as well as microbicidal activity in IFN-gamma-primed macrophages. Journal of Immunology 159, 6131-6139.

Cardillo, F., Voltarelli, J.C., Reed, S.G., Silva, J.S., 1996. Regulation of Trypanosoma cruzi infection in mice by gamma interferon and interleukin-10: role of NK cells. Infection and Immunity 64, 128-134.

Cardillo, F., Postol, E., Nihei, J., Aroeira, L.S., Nomizo, A., Mengel, J., 2007. B cells modulate $\mathrm{T}$ cells so as to favour T helper type 1 and CD8+ T-cell responses in the acute phase of Trypanosoma cruzi infection. Immunology 122, 584-595.

Carneiro, C.M., Martins-Filho, O.A.M., Reis, A.B., Veloso, V.M., Araújo, F.M.G., Bahia, M.T., Lana, M., Machado-Coelho, G.L.L., Gazzinelli, G., Correa-Oliveira, R., Tafuri, W.L., 2007. Differential impact of metacyclic and blood trypomastigotes on parasitological, serological and phenotypic features triggered during acute Trypanosoma cruzi infection in dogs. Acta Tropica 101, 120-129.

Chandrasekar, B., Melby, P.C., Troyer, D.A., Colston, J.T., Freeman, G.L., 1998. Temporal expression of pro-inflammatory cytokines and inducible nitric oxide synthase in experimental acute chagasic cardiomyopathy. American Journal of Pathology 152, 925-934.

COBEA, 2006. Colégio Brasileiro de Experimentação Animal. Legislação e ética. Available from: <http://www.cobea.org.br/>.

Conover, W.J., 1980. Practical Nonparametric Statistics, 3rd ed. Wiley, New York.

Coura, J.R., Junqueira, A.C.V., Carvalho-Moreira, C.J., Borges-Pereira, J., Albajar, P.V., 2007. Uma visão sistêmica da endemia chagásica. In: Silveira, A.C. (Ed.), La Enfermedad de Chagas a la Puerta de los 100 Años del Conocimiento de Una Endemia Americana Ancestral. Organización Panamericana de la Salud y Fundación Mundo Sano, Buenos Aires, pp. 25-35.

Cummings, K.L., Tarleton, R.L., 2004. Inducible nitric oxide synthase is not essential for control of Trypanosoma cruzi infection in mice. Infection and Immunity 72 , 4081-4089.

Dos Reis, G.A., Peçanha, L.M., Bellio, M., Previato, J.O., Mendonça-Previato, L., 2002. Glycoinositol phospholipids from Trypanosoma cruzi transmit signals to the cells of the host immune system through both ceramide and glycan chains. Microbes and Infection. 4, 1007-1013.

Green, L.C., Wagner, D.A., Gloglowski, J., Skipper, P.L., Wishnok, J.S., Tannenbaum, S.R., 1982. Analysis of nitrate, nitrite, and $(15 \mathrm{~N})$ nitrate in biological fluids. Analytical Biochemistry 126, 131-138.

Holscher, C., Kohler, G., Muller, U., Mossmann, H., Schaub, G.A., Brombacher, F., 1998 Defective nitric oxide effector functions lead to extreme susceptibility of Trypanosoma cruzi-infected mice deficient in gamma interferon receptor or inducible nitric oxide synthase. Infection and Immunity 66, 1208-1215.

Kollien, A.H., Schaub, G.A., 2000. The development of Trypanosoma cruzi in triatominae. Parasitology Today 16, 381-387.

Lana, M., Chiari, E., Tafuri, W.L., 1992. Experimental Chagas's disease in dogs. Memórias do Instituto Oswaldo Cruz 87, 59-71.

Lana, M., Tafuri, W.L., Caliari, M.V., Bambirra, E.A., Chiari, C.A., Rios Leite, V.H., Barbosa, A.J.A., Toledo, M.J.O., Chiari, E., 1988. Fase crônica cardíaca fibrosante da tripanossomíase cruzi experimental no cão. Revista da Sociedade Brasileira de Medicina Tropical 21, 113-121.

Oswald, I.P., Gazzinelli, R.T., Sher, A., James, S.L., 1992. IL-10 synergizes with IL-4 and transforming growth factor-beta to inhibit macrophage cytotoxic activity. Journal of Immunology 148, 3578-3582.

Park, C.S., Krishna, G., Ahn, M., Kang, J., Chung, W., Kim, D., Hwang, H., Lee, J., Paik, S., Cha, Y., 2000. Differential and constitutive expression of neuronal, inducible, and endothelial nitric oxide synthase mRNAs and proteins in pathologically normal human tissues. Nitric Oxide: Biology and Chemistry 4, 459-471.

Pascutti, M.F., Bottasso, O.A., Hourquescos, M.C., Wietzerbin, J., Revelli, S., 2003. Age-related increase in resistance to acute Trypanosoma cruzi infection in rats is associated with an appropriate antibody response. Scandinavian Journal of Immunology 58, 173-179.

Petray, P., Castanos-Velez, E., Grinstein, S., Orn, A., Rottenberg, M.E., 1995. Role of nitric oxide in resistance and histopathology during experimental infection with Trypanosoma cruzi. Immunological Letters 47, 121-126.

Prata, A., 2001. Clinical and epidemiological aspects of Chagas disease. Lancet Infectious Disease 1, 92-100. 
Rottenberg, M.E., Bakhiet, M., Olsson, T., 1993. Differential susceptibilities of mice genomically deleted of CD4 and CD8 to infections with Trypanosoma cruzi or Trypanosoma brucei. Infection and Immunity 61, 5129-5133.

Rottenberg, M.E., Riarte, A., Sporrong, L., 1995. Outcome of infection with different strains of Trypanosoma cruzi in mice lacking CD4 and/or CD8. Immunological Letters 45, 53-60.

Russo, M., Minoprio, P., Coutinho, A., Hontebeyrie-Joskowicz, M., 1988. Depletion of $\mathrm{L} \mathrm{T}_{4}{ }^{+} \mathrm{T}$ lymphocytes during acute Trypanosoma cruzi infection abolishes macrophage and B lymphocyte activation but not tissue inflammatory reaction. Memórias do Instituto Oswaldo Cruz 83, 527-538.

Saeftel, M., Fleischer, B., Hoerauf, A., 2001. Stage-dependent role of nitric oxide in the control of Trypanosoma cruzi infection. Infection and Immunity 69, 22522259.

Sandler, S.G., Yu, H., Rassai, N., 2003. Risks of blood transfusion and their prevention. Clinical Advances in Hematology and Oncology 1, 307-313.
Sardinha, L.R., Elias, R.M., Mosca, T., 2006. Contribution of NK, NK T, gammadelta T, and alphabeta $\mathrm{T}$ cells to the gamma interferon response required for liver protection against Trypanosoma cruzi. Infection and Immunity 74, 2031-2042.

Sher, A., Gazzinelli, R.T., Oswald, I.P., Clerici, M., Kulberg, M., Pearce, E.J., Berzofsky, J.A. Mosmann, T.M. James, S.L. Morce, H.C. Shearer, G. 1992. Role of T-cell derived cytokines in the downregulation of immune responses in parasitic and retroviral infection. Immunological Reviews 127, 183-204.

Taylor-Robinson, A.W., Liew, F.Y., Severn, A., Xu, D., McSorley, S.J., Garside, P., Padron, J., Phillips, R.S., 1994. Regulation of the immune response by nitric oxide differentially produced by T helper type 1 and T helper type 2 cells. European Journal of Immunology 24, 980-984.

Vespa, G.N., Cunha, F.Q., Silva, J.S., 1994. Nitric oxide is involved in the control of Trypanosoma cruzi-induced parasitemia and directly kills the parasite in vitro. Infection and Immunity 62, 5177-5182. 